\title{
PACKING AND UNPACKING GRAMMAR - TOWARDS A COMMUNICATIVE APPROACH TO TEACHING LANGUAGE STRUCTURES
}

\author{
Isabela-Anda DRAGOMIR \\ izadragomir@yahoo.com \\ Brânduşa-Oana NICULESCU \\ branducosma@yahoo.com
}

“NICOLAE BĂLCESCU” LAND FORCES ACADEMY, SIBIU, ROMANIA

\begin{abstract}
Creating classroom activities which really get students to communicate in a natural and meaningful way remains a timely challenge when it comes to teaching a foreign language. This article sets out to revisit the traditional trifecta based on the three Ps (presentation, practice, production) and reincorporate it in a set of specific elements that ensure a successful outcome of language learning activities. With particular focus on grammar, the paper aims to deconstruct the steps and procedures behind five important aspects to be taken into consideration when planning and conducting activities that target structures of language and their practice in a communicative manner, with the ultimate goal of linking the often sterile theory of grammar with contextualized models and tasks.
\end{abstract}

\section{KEYWORDS:}

Language teaching, grammar, language structures, communicative approach

\section{Introduction}

The overarching objective of language teaching is to create long-lasting abilities for communication in the target language. In contrast to traditional approaches, which mainly focus on often isolated grammatical competence, communicative language teaching pivots on building communication skills, relevant and applicable in real-life contexts. This reorientation stems from the belief that since language is intended to be used in real communicative situations, learners' inherent strategies are more naturally activated in authentic contexts, which will allow them to internalize language in use.
In coping with learning a foreign language, confidence plays an essential part. Students need to feel that they will be able to relevantly use the information they have assimilated in the classroom by applying it to real life. Genuine communication contexts require learners to master the ability of dealing with many diverse situations, in a foreign language, by interacting with a wide array of language speakers. Revell (2013) argues that one of the main roles of the teacher is to provide students with opportunities to build on their confidence, by providing communicative frameworks for them to practice what they have learnt 
in as realistic a way as possible inside the classroom. Student-centered approaches advocate emphasis on natural contextualizations of the language, on creating situations that offer learners opportunities to experiment with the newly-acquired linguistic skills, while expressing their creativity. Consequently, classroom activities should be designed so as to successfully bridge the gap between skill-getting and skill-using.

Developing communicative competence is an endeavor that requires an interdependent combination of language elements (vocabulary, grammar, pronunciation) and skills (especially the productive ones, i.e. speaking and writing). With specific focus on teaching and practicing grammar, this paper aims to take a detailed look at the steps and procedures behind five important aspects to be taken into consideration when planning and conducting activities that target structures of language and their practice in a communicative manner, with the ultimate goal of linking the often sterile theory of grammar with contextualized models and tasks.

\section{Teaching grammar - a tale of two approaches}

The key to teaching grammar communicatively consists in presenting language in a manner that corresponds with the ways that our brains actually process and encode language rather than providing students with lists and explanations that decontextualize grammar and make it an unrelatable, nebulous grouping of rules that seemingly contradict each other and have nothing to do with the way we actually process information.

When dealing with the teaching of grammar, scholars have traditionally taken two major avenues: explicit and implicit approaches. Explicit teaching focuses on grammar rules, i.e. knowledge that can be applied consciously; implicit teaching, with emphasis on intuitive knowledge, exposes learners to more natural acquisition. The recommendation of the specialists is to use "a twin-track approach", targeting both explicit knowledge (through consciousnessraising) and opportunities for real language use (Thornbury, 2019). The great benefit of this approach is that it juxtaposes the traditional grammar syllabus, including structure items, or language "chunks" (e.g. tenses, comparative and superlative structures, modals and their equivalents, "if-clause" structures) with communicative practice, i.e. teacherguided contextualizations that facilitate a more naturalistic acquisition of the target language. Such an approach becomes even more so advantageous since, as Ellis and Shintani (2004) concluded, "grammatical syllabuses cannot easily accommodate the essential nature of L2 acquisition".

At early stages, grammar learning takes the form of item-learning, with students memorizing and using formulaic sequences, which serve as a "starter pack" from which language is generated. Later on, as students become more autonomous and confident with deploying language creativity, fluency prevails over accuracy and the focus of language production shifts from form to content, i.e. the message to be transmitted in diverse communicative instances. The final conclusion is that the best type of foreign language instruction is the one that integrates both implicit and explicit approaches. As Dörney (2009) argues, the two systems must function cooperatively, with explicit knowledge "filling the gaps" when implicit knowledge fails.

\section{Teaching communicative competence through grammar}

According to Bahar (2013), learning English is not an isolated process of mastering grammar rules, with focus on building correct sentences, but has to be seen as a process of developing both accuracy and fluency by resorting to the functional and social aspects of the language. Any discussion about building functional skills should start from the conceptual divide existing between linguistic competence and communicative competence. 
The real challenge is to efficiently bridge the gap between skill-getting and skillusing, basically ensuring a smooth transition between acquisition and functionality. In order to do so, teachers must transform the often sterile classroom environment into a natural locus of authentic expression of thoughts, ideas and information. Since communication stems from necessity, it is exactly this aspect that needs to be taken into consideration and created in the classroom.

In this paper, we intend to advocate a blending of five ingredients that are aimed at ensuring a successful outcome of communicative language learning activities. These are: contextualization, noticing, processing, practice, and feedback. A welldesigned task incorporates all these elements in a natural way, by integrating practice opportunities into a realistic context, while focusing the learners' awareness regarding form and meaning and by creating feedback opportunities for the regulation of the final product. In a nutshell, this approach can be summarized through the following three steps:

1. Contextualize function;

2. Emphasize meaning;

3. Create language.

Contextualization is directly related to the input received by students. For any given communicative task the input may take the form of a picture, a video, a text, basically any package of information that helps set the stage and create the need to communicate. In order to maximize the potential of the input for future language use, an effective approach would be to unpack its contextualized features (register, setting, time, topic, type, manner) by discussing specific information which facilitates the assignment of meaning to the situation, through explicit application of grammar elements (in this context, question formulation: who, where, when, why, what, etc.). Thus, language is internalized through meaningful deconstruction and unpacked so as to provide discrete elements for future use, with focus on particular functions (description, narration, comparison and contrast, etc.)

The following logical step is to further focus on these deconstructed elements. As previously mentioned, noticing channels language practice explicitly, through inductive (focusing on examples) and deductive (providing clear explanations) methods. The objective of this stage is to check understanding and concept-related knowledge by drawing attention on form, spelling, and pronunciation of the target structures. Such activities work best with discrete elements of grammar, such as irregular verbs or noun plurals, tenses, the comparative of adjectives and adverbs, etc.

Processing is a more complex step in which input and context are united under the umbrella of meaning. Examples of language use are provided so as students get a chance to sink in the bigger picture for the comprehension of which they need to activate previous knowledge, identify links between already studied content and use critical thinking skills. In order for processing to happen naturally and effortlessly, it is indicated that tasks be personalized and inserted in a familiar situation that is related to real-life occurrences. Given that the ultimate goal of language use is to communicate reality, it is only logical that processing utilizes recognizable concepts students can employ in an innate manner.

The scaffolding created through the accumulation of contextualization, noticing and processing activities supports the most important element of this recipe - practice. Language can be practiced through a wide array of tasks, either oral or written, whose undeniable goal is to communicate meaning by deploying language functions that incorporate the target structures. The practice tasks must be challenging and attractive, in order to motivate learners to engage actively. Moreover, from a methodological point of view, they must combine receptive and productive skills and be measurable, achievable, realistic, function-based and goal-oriented. Depending on their objective, 
communicative tasks may or may not target specific language. As a general example, such tasks can range from free speaking to specific conversations, role-plays, simulations, essay writing, or even drawing or building different things.

Last but not least, feedback is the ultimate essential piece of the puzzle. Ideally, it should link back to a feed-forward sequence, which explains expectations and establishes performance indicators and standards. Furthermore, experience has demonstrated that feedback works best if presented against the background of a comparison between the students' output and a previously-provided ideal sample. Thus, the teacher's expectations are clarified against a specific example that incorporates all the elements students are required to produce, in terms of format, organization, content, language, delivery, and pronunciation/ mechanics.

By and large, all these elements converge towards a structured internalization of language, aimed at establishing a logical sequence for the unpacking and packing of the discrete elements to be taught/learned.

\section{An illustration of communicative grammar practice}

Starting from the idea that theory is best put in practice through exemplification, we will provide an applicative example of a five-step task that incorporates all the above mentioned elements with the aim of helping students acquire confident functionality related to a specific language structure conditional clauses.

Students are presented with constructions that deploy hypothetical formulations ("if clauses" types II and III) with specific focus on unlikely situations with probable results (type II) and on impossible, unreal conditions in the past (type III). In addition to emphasizing the grammatical structure specific to each type (tense combinations in the main clause and the subordinate clause), the main objective here is to differentiate between hypothetical situations that are unreal but probable, on the one hand, and unreal and impossible, on the other. The language function targeted by the application of this sequence is hypothesizing, i.e. the ability the students will acquire and use in order to analyze, discuss and interpret different situations that may occur in real life. Besides the cognitive skills that are definitely needed and activated in this context, students should be able to effectively employ the linguistic instruments that allow them to verbalize imaginary and speculative conditions and their results.

The first stage of this complex activity requires relevant contextualization, which sets the stage for the authentic use of the target language structure. In the first exercise, students are required to match the "if clause" with the appropriate "main clause", in order to recreate a logical and coherent sentence.

\section{Match the two halves in order to build a logical sentence:}
a. If I had studied harder for this exam, ... .
1. I wouldn't get any pocket money.
b. If I ever felt I had too much money, ... .
2. I would have sent you an invitation.
c. If I had known that they were valuable
3. I would give it away to charity. antiques, ....
d. If I didn't behave well, ... .
4. I would travel all over the world.
e. If I were single with no kids and no
5. I would have kept them. responsibilities, .... .
f. If I had known the address, ... .
6. I would have passed it. 
After completing this task, a followup activity would require students to discuss the sentences, by deconstructing their meaning through rephrasing and by identifying the type of situation expressed in each sentence. The answers may vary, but students should differentiate between unreal but possible conditions (sentences $\mathrm{b}, \mathrm{d}, \mathrm{e}$ ) and unreal and impossible situations (sentences a, c, f).

The next step is noticing, more specifically emphasizing form. Given the fact that we are dealing with two types of "if clauses", the conditional structure will be fixed by deconstructing the grammatical elements of the sentences: past tense + present conditional for type II and past perfect + perfect conditional for type III. By applying an inductive approach, students will start from the provided examples and extract the tense combinations based on a pattern of repetition they identify in the two sets of sentences. Guided practice at this stage could require students to complete the missing structures in conditional formulations, either by inserting the "if clause" verb or the main clause one. A more complex variation of this type of exercise could be one in which the verb is not provided, thus complementing structure practice with vocabulary reactivation, by having students come up with a verb they consider appropriate to the context.

\section{Complete the sentences with the correct form of the verb in brackets:}

1. If I (have) enough money, I would go with you on that trip.

2. If I had had more money, I (go) with you on that trip.

3. If I had a camera with me, I (take) a lot of pictures.

4. If I (have) a camera yesterday, I would have taken a lot of pictures.

5. If she came to the party tonight, she (meet) my brother.

6. If she (come) to the party, she would have met my brother.

If in the previous stage, the teacher acted as a resource and assumed more control over the information to be transmitted, i.e. providing the theoretical framework, the following stage of the activity involves students more actively, in that they will be required to process the newly-acquired structures, by practicing their use in meaningful, realistic and familiar contexts.

\section{Finish the sentences with your own ideas:}

1. If I won the lottery,

2. If I could travel anywhere in the world,

3. If I could change anything about my past,

4. If I had not joined this Academy,

5. If I had known more foreign languages,

6. If I had been born in the Middle Ages, 
Although there will definitely be an extensive variance of answers, the focus should be on the correct use of the form and on the structural and lexical accuracy of the sentences. Creativity should also be encouraged, as students should feel free to express their thoughts and personalize their answers for a better and more significant internalization of the target structure.

Language practice involves communicative tasks to be solved either orally or in writing. For oral practice, we propose a paired activity based on rephrasing a given cue by using a conditional construction. Students will take turns in reading each other a situation that needs to be transformed into an "if clause". The two skills to be deployed in this exercise are listening and speaking, while the language to be used is produced by recycling the input and contextualizing the target structures (conditionals).

\section{Listen to the sentence your colleague reads and make an "if clause" sentence}

based on it:

1. You want to buy a new car, but you do not have enough money.

2. I would like to visit the United States, but I do not have a visa.

3. I am sweating because it is very hot here.

4. You had an accident because you weren't watching the road.

5. I didn't enjoy school so I didn't do very well as a student.

6. You wanted to come to the concert with me, but I forgot to buy a ticket for you.

A more complex activity may involve the production of a written paragraph on a given hypothetical situation. Students are expected to produce a series of elaborate conditional sentences, presenting their own ideas and suggestions in a hypothetical manner. The advantage of such a task is that it does not target a specific lexical area, but focuses on transmitting meaningful information. The exercise is also challenging and relevant, in that it takes students out of their comfort zone by having them imagine they are somebody else, allows room for creativity and expression of subjective experience and may result in a tangible outcome, which anchors the learning experience deeper into the a communicative reality. Another secondary focus here might be a purely writing element - paragraph structure. Students should be instructed to respect composition rules in terms of organization (having introduction, body and conclusion) and cohesion and coherence (logically linking main points and supporting details).

\section{$\mathrm{V}$. Write a 150-word paragraph in response to the following situation:}

What three changes would you make to improve the curriculum of the Land Forces Academy if you were the Commandant of this military institution? 
Feedback is an essential stage of any instructional sequence. It has a dual purpose: it is both corrective and praising. It could be teacher-generated, peergenerated or may take the form of selfevaluation. Comprehensive and pertinent feedback should include clear expectations, criteria, standards, performance indicators and also encourage remedial discussions based on an ideal sample. For the presented activity, we propose a self-assessment tool that facilitates autonomous evaluation of the students' own work, that diagnoses the written product in terms of "what" (expectations) and "how" (indicators).

\begin{tabular}{|c|c|c|c|}
\hline \multicolumn{4}{|l|}{ SELF-CHECK LIST } \\
\hline \multirow[b]{2}{*}{ I have introduction (I), body (B), conclusion (C). } & I & $\mathrm{B}$ & $\mathrm{C}$ \\
\hline & & & \\
\hline \multicolumn{4}{|l|}{ I wrote my own ideas. } \\
\hline \multicolumn{4}{|l|}{ I mentioned three measures. } \\
\hline \multicolumn{4}{|l|}{ I used at least 3 conditional constructions. } \\
\hline I used at least 5 connectives (sequence, addition, cause-effect, summation). & & & \\
\hline
\end{tabular}

We appreciate this self-check list to be a simple but useful self-regulatory instrument that helps students understand their work and channel their efforts towards improving their performance before submitting it for final evaluation by the teacher.

\section{Conclusion}

Teaching grammar communicatively is underlined by three main pillars that are meant to ensure an effective mastery of the language: context, meaning, and practice. First of all, we have insisted on the authenticity of contextualization. Against this backdrop, language practice needs to provide full contents of the structures, their usage and meaning, as well as some samples for students to redo, revisit, and reactivate in real situations. Secondly, emphasis on meaning draws on the importance of noticing and processing language in ways that are comprehensible and easy to remember. Information about language should be provided in situations that are clear, useful, practical, and relevant in daily situations. Last but not least, practice should provide sufficient instances that facilitate and build on the learners' ability to create language, taking the learning process one step further from the mere repetition of model sentences and establishing a framework for a meaningful and original usage of the language.

The type of classroom activities proposed in this paper also implies new roles for teachers and learners alike. The teacher becomes a facilitator and a monitor, rather than an instructor, while the students take more responsibility for their own learning. Practice and production are based on cooperation, rather than on an individualistic approach to learning, situating students in more comfortable situations, where they can develop authentic language and cognitive skills that are required in the shared reality they are expected to be part of, regardless of the language they use to transmit meaning. 


\section{REFERENCES}

Bahar, A.K. (2013). The Communicative Competence-Based English Language Teaching. Yogyakarta: TrustMedia.

Dörney, Z. (2009). The Psychology of Second Language Acquisition. Oxford: Oxford University Press.

Ellis, R., \& Shintani, N. (2014). Exploring Language Pedagogy through Second Language Acquisition Research. London: Routledge.

Larsen-Freeman, D. (2015). Research into practice: Grammar Learning and Teaching. Language Teaching. Vol. 48, Issue 2, 263-280, available at: https://www.proquest.com/ docview/1662817287?accountid=205946, accessed on 16 November 2021.

Revell, J. (2013). Teaching Techniques for Communicative English. London: HarperCollins Publishers.

Thornbury, S. (2019). Teaching Grammar to Adults. Part of the Cambridge Papers in ELT series. [pdf] Cambridge: Cambridge University Press, available at: CambridgePapersInELT TeachGrammarAdults 2019 ONLINE.pdf, accessed on 16 November 2021. 